\title{
Relationship between Adolescents' Health Beliefs and Health Behavior
}

\author{
Gayathri Shabaraya ${ }^{1}$, Romate $\mathrm{J}^{2}$, Sudha Bhogle ${ }^{3}$ \\ ${ }_{1}^{1}$ GFATM-7, Centre for Psychological Counselling, Bangalore University, Bangalore, India. \\ ${ }^{2}$ Centre for Psychological Counselling, Bangalore University, Bangalore, India. ${ }^{3}$ Eduquity Career Technologies, Bangalore, India
}

\section{A B STRACT}

\begin{abstract}
Aim: This study aims to determine the relationship between Health Behavior and Health Locus of Control among 1270 adolescents (Boys $\mathrm{N}=635$ and Girls $=635$ ) who were drawn from Bangalore rural and urban district government high schools (mean age 13.76 years). Methodology: The Global School based Health survey (WHO, 2004) and Multidimensional Health Locus of Control by Wallston and Wallston, questionnaires were used to assess health locus of control and health behavior respectively. The data obtained was subjected to statistical analysis using Pearson's product moment correlation methods to examine the relationship between these variables. Results and Interpretation: Findings revealed that total health behavior score of adolescents is significantly correlated with 'internal' and 'powerful others' dimensions of health locus of control. Further, the 'chance factor' of health locus of control did not show any significant relationship with the total health behavior score. From this it can be inferred that adolescents with high inclinations towards 'internal health locus of control' and 'powerful others' have healthier dimensions of positive behaviors. Findings have also revealed that health behavior is not significantly correlated with the beliefs that 'health is a function of chance/luck'.
\end{abstract}

Key words: Health Behavior, Health Locus of Control, Adolescents, School health

\section{INTRODUCTION}

Adolescence, the transitional period between childhood and adulthood, is marked by changes in the body, mind and social relationships. As teenagers confront these challenging years, they develop a sense of understanding of their psychological, social and physical growth and changes and gradually construct their own ideas and beliefs on various health related aspects; that is, some sense of the extent to which they feel in control of important aspects of their lives. This is one of the many areas in which there has been a significant amount of interest shown by researchers in relating locus of control (LOC) beliefs to a variety of relevant behaviors. Health is generally looked upon as one of the most imperative factors that lead to the enhancement of quality of life and wellbeing. Social and behavioral scientists have defined health as a dynamic and ongoing facet of human growth and development which greatly depends upon the behavior of individuals.

Address for correspondence:

E-mail: psygayathri@gmail.com

DOI: 10.5530/ijmedph.3.2011.9
Mosby's Medical Dictionary ${ }^{1}$ defines health behavior as an action or activity taken by a person to maintain, attain or regain good health and to prevent illness. Hence, health behavior is beyond the visible actions such as eating, exercising, relaxing, etc. It also includes various abstract interpersonal and intrapersonal processes like, cognitive and affective processes including attitudes, beliefs, behaviors and situational factors which play a vital role in enhancing and maintaining the quality of healthy life. Thus, the action or activity resulting in 'good health' through various dynamic processes can be referred to as 'positive health behavior'. ${ }^{2}$

The need to maintain positive health behavior has become a subject matter of exploration by social and behavioral scientists during the last few decades. Kasl and $\mathrm{Cobb}^{3}$ have conceptualized three categories of health behavior 'preventive health behavior' which implies any action taken by a healthy individual for the purpose of preventing or detecting illness; 'illness behavior' which implies that an individual, who perceives himself to be ill, takes up remedial measure to get healthy and 'Sick-role behavior' which refers to an action taken by an individual who considers himself to be ill, for the purpose of getting well.

Gochman ${ }^{4}$ has broadly defined health behavior as: those personal attributes such as beliefs, expectations, motives, 
values, perceptions, and other cognitive elements; personality characteristics including affective and emotional states and traits; and overt behavior patterns, actions, and habits that relate to health maintenance, to health restoration, and to health improvement. There are social norms too which play a significant role in intra and inter individual differences. ${ }^{5}$ Therefore, developing positive health behavior and maintaining it largely depends on various factors like individual's belief system, cognitive attributes along with social influence.

The term 'Locus of control' refers to the extent to which individuals believe that they can control events that affect them. ${ }^{6}$ Individuals with a high internal locus of control believe that events result primarily from their own behavior and actions. Those with a low internal locus of control believe that powerful others, fate, or chance primarily determines events. Those with a high internal locus of control have better control of their behavior, tend to exhibit more opinionated behaviors, and are more likely to attempt to influence other people than those with a high external (or low internal respectively) locus of control. Those with a high internal locus of control are more likely to assume that their efforts will be successful. They are more active in seeking information and knowledge concerning their situation. Since locus of control is believed to have been based on social learning theory, which emphasises on history of reinforcement, there could be considerable strong association between health behavior and locus of control. ${ }^{7}$

Empirical data on health locus of control in various fields have been extensively reviewed and reported by Norman and Bennett. ${ }^{8}$ These authors have noted that, data on certain health-related behaviors related to internal health locus of control have been ambiguous. For example, they note that, internal health locus of control is linked with increased exercise, however, they also cite several studies that have found only a weak or no relationship between exercise behaviors (such as jogging) and internal health locus of control. They note similar ambiguity for data on the relationship between internal health locus of control and other health-related behaviors, such as breast selfexamination, weight control and preventative health behaviors. Of particular interest are the data these authors cite on the relationship between internal health locus of control and alcohol consumption.

Norman and Bennett ${ }^{8}$ note that some studies that compared alcoholics with non-alcoholics suggest that alcoholism is linked to increased externality for health locus of control, but other studies have found alcoholism to be linked with increased internality, and similar ambiguity has been found in studies that looked at alcohol consumption in a more general, non-alcoholic population. Norman and Bennett ${ }^{8}$ appear a little more optimistic in reviewing the literature on the relationship between internal health locus of control and smoking cessation, although they also point out that there are grounds for supposing that powerful others health locus of control, as well as internal health locus of control, may be linked with smoking cessation.

Lefcourt ${ }^{7}$ argues that behavior-specific health locus scales have tended to produce more positive results than general locus of control scales. Norman and Bennett ${ }^{8}$ reviewed and reported several findings that have been published using health-related locus of control scales in specific domains, such as cancer, diabetes, tablet-treated diabetes and hypertension. ${ }^{9-11}$ These findings reveal that health locus of control is better at predicting health-related behavior if examined in conjunction with health value, i.e. the value people attach to their health, suggesting that health value is an important moderator variable in the health locus of control relationship. However, Maltby, Day and Macaskill, ${ }^{12}$ cite studies linking internal locus of control with improved physical health, mental health and quality of life in people undergoing conditions as diverse as HIV, migraines, diabetes, kidney disease and epilepsy ${ }^{12}$ using general measures of locus of control despite the importance that attach to use of specific measures of locus of control argued by Lefcourt ${ }^{7}$ and Norman and Bennett. ${ }^{8}$

The existing literature points out a significant relationship between the dimensions of locus of control with positive aspects of health behaviour. ${ }^{13,14}$ In the light of the findings reviewed above it necessitates an exploration of the relationship between health behavior and locus of control. Further, it is found to be interesting to examine how the dimensions of positive health behaviors - Dietary Behavior, Violence and Unintentional Injury, Hygiene, Mental Health, Tobacco use, Alcohol and Other drug use, Physical Activity, Protective Factor and Sexual Behavior are associated with the various dimensions of locus of control. Hence, this study is designed with the following objective.

\section{METHODOLOGY}

\section{Objective}

To study the relationship between the dimensions of Health behavior and Health locus of control among Adolescents

\section{Sample}

The study was carried out among 1270 government high schools students who were drawn from Bangalore urban district, government schools. The sample was drawn using a stratified sampling method, from Bangalore north, south, east, west and central regions. The age of the 
sample ranged between 13-16 years with the mean age of 13.76 years [S.D. 1.76].

\section{Ethical policy}

The research protocol was approved by the Bangalore University $\mathrm{PhD}$ committee. The informed consent was obtained from subject prior to the inclusion in the study.

\section{Measures}

Personal and socio demographic details of the subjects were obtained and verified prior to the administration of the Global School Bases Health Assessment (GSHS) and the Multi dimensional Health Locus of control questionnaires on the sample. The Global School Based Health Assessment (GSHS) used in the present study was developed by the World Health Organization in collaboration with United Nations' UNICEF, UNESCO, CDC and UNAIDS. GSHS is a school- based assessment, which is generally used among students within the age range of 13 to 15 years, consists of fifty-two items representing ten major dimensions of health behavior such as dietary behavior, hygiene, mental health, tobacco use, violence and unintentional injury, alcohol and other drugs use, physical activity, protective factors and sexual behaviors. These ten dimensions address the leading causes of morbidity and mortality among children and adult worldwide. ${ }^{15-17}$ Each item in the questionnaire has slightly different point response ranging from two points to seven points. Lower scores indicate better health behavior and high scores indicates vice versa.

The Multi dimensional Health Locus of control scale used in the present study was developed by Wallston and Wallston. ${ }^{18}$ The questionnaire consists of eighteen items representing three dimensions, with six items in each. These dimensions are namely, Internal Health Locus of Control
(IHLC), Powerful others (PHLC) and Chance factor (CHLC). Internal Health Locus of Control assesses the degree to which an individual believes health is a function of personal behavior and measures whether one feels that one has personal control over one's health. Powerful others Health locus of Control assesses the belief that one's health is determined by such important persons as physicians, other health professionals, and family members and measures whether one feels that others such as physicians control their health. Chance Health Locus of control measures the extent to which one considers health to be a function of luck/chance. The response of each item in a particular sub scale is summed up to obtain the respective scores of each dimension.

\section{Analysis of data}

The statistical analyses were done using SPSS. The descriptive statistical methods were used to profile the sample and to observe the overall characterises across the assessed variables. The inferential statistical methods were employed to assess and examine the association between health behavior and the health locus of control.

\section{RESULTS}

The descriptive statistics i.e. the mean score and SD on Health behavior, its dimensions and Health Locus of Control are shown in table 1 . The maximum and minimum score obtainable for each variable is also presented. Low score on Health behavior indicates good health behavior i.e. if the score of zero is obtained, it indicates good Health behavior and vice versa. The scores were converted into percentile i.e. 1 to 10 scale; The multidimensional Health Locus of Control scale ${ }^{18}$ was used to assess the three sub dimensions of LOC, namely Internal Locus of control,

\begin{tabular}{|c|c|c|c|c|}
\hline SI. No & Variables & Mean & SD & Max/ min obtainable \\
\hline \multicolumn{5}{|c|}{ Health Behavior } \\
\hline 1 & Dietary Behavior & 07.04 & 3.06 & $0-16$ \\
\hline 2 & Hygiene & 03.82 & 2.55 & $0-15$ \\
\hline 3 & Violence and Unintentional Injury & 10.40 & 6.97 & $0-46$ \\
\hline 4 & Mental Health & 03.79 & 2.97 & $0-14$ \\
\hline 5 & Tobacco use & 01.56 & 2.48 & $0-30$ \\
\hline 6 & Alcohol and Other drug use & 00.61 & 2.03 & $0-28$ \\
\hline 7 & Physical Activity & 11.69 & 7.19 & $0-27$ \\
\hline 8 & Protective Factor & 04.69 & 3.96 & $0-20$ \\
\hline 9 & Sexual Behavior & 00.32 & 1.44 & $0-16$ \\
\hline 10 & Global Health Behavior Total & 43.93 & 15.5 & $0-212$ \\
\hline \multicolumn{5}{|c|}{ Health Locus of Control } \\
\hline 11 & Internal Locus of Control & 28.8 & 4.91 & $6-36$ \\
\hline 12 & Chance factors & 23.2 & 5.28 & $6-36$ \\
\hline 13 & Powerful others & 27.0 & 4.79 & $6-36$ \\
\hline
\end{tabular}


powerful other- locus of control and Chance factor- Locus of control. Higher score on each sub scale indicates that the higher the inclination towards internal, powerful others and chance factor - locus of control.

The mean score and SDs of the three dimensions of Health Locus of Control are viz internal dimension was 28.8 (SD 4.91), chance factor 23.2 (SD 5.28) and powerful other 27.9 (SD 4.79) indicating that adolescents rated high on 'inclination towards internal' and 'powerful other dimensions' compared to the 'chance factor' dimension in the locus of control scale. This result implies that adolescents feel that they have greater control over their health along with the influence of their parents and doctor/s; however, they do not feel fate controls their health.

Table 2 depicts the Pearson's product moment correlations between the different dimensions of health behavior and health locus of control. As can be seen from the table, the 'chance factor' in locus of control does not correlate with any dimension of health behavior.

Considering the other two dimensions of locus of control viz., internal and powerful others - similar results emerge. Diet as a dimension of health behavior does not correlate with any of the three dimensions of locus of control. All the other eight dimensions, as well as the total score are negatively and significantly correlated, indicating that higher the scores on the specific aspect of locus of control, lower the scores on positive health behavior. Total health behavior score is significantly and inversely correlated with the 'internal' factor $(r=-.114<0.01)$ indicating that more the internality in health locus of control, more positive is health behavior. Similarly, The correlation between 'powerful others' dimension of health locus of control $(r=-.155<0.01)$ and total health behavior implies that adolescents who possess better positive health behavior feel that they need to keep in touch with doctors or other health practitioners, for enhancing the health behavior.

\section{DISCUSSION}

The main aim of this study was to determine the relationship between Health Locus of Control and positive health behaviors of adolescent students. The present findings reinforce the need to understand how an adolescents' health behavior is correlated with his locus of control. The profile of health behavior and health locus of control that has emerged from this study reveals that the adolescents of this study are less involved in unhealthy activities pertaining to the dimensions of the following health behaviors - 'Alcohol and other drug abuse', 'sexual behavior' and 'tobacco use'. On the contrary, on other dimensions like 'Dietary behavior' and 'Physical activities' the results indicate an inclination towards unhealthy behaviors. Understanding the fact that various socio, economical, cultural factors could play a vital role in shaping positive health behavior among adolescents, a close look at Dietary behavior indicates that mere availability of adequate food could be an important factor influencing their scores in this domain. It is to be noted here that in the present study, subjects were drawn from government school population hailing from lower and middle socio economic strata who, many a times, could not afford to have the minimum required quantity and quality of nutritious food. The scores on 'poor physical activities' could once again be a reflection of the socio economic milieu from which these students come. Inadequate infrastructure in schools and a school environment which prioritizes curriculum learning rather than providing opportunities for extra curricular activities could have made them less physically active.

These findings are consistent with other research on similar samples. A study conducted among adolescents $(\mathrm{N}=680)$ revealed that the health behavior dimensions of "Tobacco

\begin{tabular}{lccc}
\multicolumn{4}{c}{ Table 2: Inter Correlation between dimensions of Health Behavior and Health locus of control } \\
\hline \multicolumn{1}{c}{ Variables } & $\begin{array}{c}\text { Health Locus of } \\
\text { Control- internal }\end{array}$ & $\begin{array}{c}\text { Health Locus of } \\
\text { Control chance }\end{array}$ & $\begin{array}{c}\text { Health Locus of } \\
\text { Control-powerful others }\end{array}$ \\
\hline Diet & -0.008 & 0.04 & -0.004 \\
Hygiene & $-.081\left(^{* *}\right)$ & 0.032 & $-.091\left(^{* *}\right)$ \\
Violence & $\left.-.090^{* *}\right)$ & -0.007 & $-.128\left(^{* *}\right)$ \\
Mental & $\left.-.172^{* *}\right)$ & -0.013 & $-.200\left(^{* *}\right)$ \\
Tobacco & $-.074\left(^{* *}\right)$ & -0.016 & $-.085\left(^{* *}\right)$ \\
Alcohol & $-.114\left(^{* *}\right)$ & -0.017 & $-.109\left(^{* *}\right)$ \\
Physical Activity & $\left.-.083^{* *}\right)$ & 0.019 & $-.056\left(^{*}\right)$ \\
Protective Factor & $-.109\left(^{* *}\right)$ & 0.008 & $-.132\left(^{* *}\right)$ \\
Sexual Behavior & $-.104\left(^{* *}\right)$ & -0.02 & $\left.-.082^{* *}\right)$ \\
Total health behavior & $-.114\left(^{* *}\right)$ & 0.011 & $\left.-.155^{* *}\right)$ \\
\hline
\end{tabular}

$(* *)$ Significant at 0.01 level

(*) Significant at 0.05 level 
use' and 'alcohol and other drug use' were found to be better when compared to the other dimensions of positive Health Behavior. ${ }^{19}$ In this context, it is to be noted from Granner's ${ }^{20}$ comments that, fruit and vegetable availability was the most consistent associate of intake of adolescents. While fruit preference, family dinner frequency, fruit and vegetable availability were the strongest associates of intake, a significant difference was also observed in the intake of protective foods like milk and milk products, green leafy vegetables and fruits between the two income groups. ${ }^{21}$

\section{Health behavior and Health Locus of control:}

The loci of control and positive health behaviors have shown a statistically significant relationship, in the present study. Akin to the results of the present study, preceding studies have reported that a positive relationship exists between the internal health locus of control and health promoting behaviours. ${ }^{22}$ Results of a few studies illustrate that there is significant positive relationship between internal health locus of control and participation in behaviors to lead a healthy life. The researchers have found powerful others sub dimension to play a vital role in engaging an adolescent in positive health behavior. Thus, it could be proposed that those with a combination of strong belief in internal control of health, high degree of belief that health is determined by powerful others, and low degree of belief that health is a function of chance/luck, had better health behavior than those with a quite opposite pattern.

When the specific dimensions are studied, the following picture emerges:

'Dietary behavior' did not show any significant relationship with all three dimensions of health locus of control. As mentioned earlier, adolescent sample in the present study was drawn from low socio economic status population where they did not have any direct role to decide on the quality and quantity of the food. Thus, the dietary behavior under such circumstances are usually monitored and shaped by the significant family members in our social scenario.

\section{Hygiene}

The hygiene dimension of health behavior is significantly correlated with both internal and powerful others dimensions' of health locus of control implying that adolescents' perception that he/she has control over health is significantly associated with the 'cleanliness' factor. At the same time, belief that significant others like doctors and parents have control over their health also is also significantly correlated with an adolescents' hygiene behavior.

\section{Violence and Unintentional Injury}

The findings indicate that more the adolescents believe that their health is under their own control, lesser is their involvement in violent behavior. A few studies reveal that violence and unintentional injuries are mostly related to sports activities that occur in school ground or yard or on the parking lot. ${ }^{23}$ Therefore it could be understood that adolescents who are inclined towards internal health locus of control and have belief in powerful others are less likely to get into school fights and bullying peer group.

\section{Mental health}

The results indicate that, the greater the adolescents' belief that health is under their parents and doctors control, better is the mental health. On the other hand it also indicates that suicidal thoughts and loneliness feeling are directly related to the amount of internal control an adolescent has. ${ }^{24}$

\section{Tobacco use}

The results imply that adolescents with less belief that their health is under their control, are at greater risk of using tobacco. It was found that the smoking status of a person made difference in a few studies, with regard to the locus of control dimensions. Compared to the smokers, nonsmokers had showed more belief in the importance of powerful others or internal locus of control. ${ }^{25}$

\section{Alcohol and other drug abuse}

The results imply that adolescents have a greater tendency to abuse alcohol if they believe that they have no control over their health. Moreover, if they are exposed to alcohol and drugs through their elders or peers, there are chances that they might get influenced to use alcohol, because their belief on powerful others locus of control is high as well. Earlier studies indicated that health locus of control was a significant predictor to alcohol abuse..$^{26,27}$ The findings of the present study also support the above views.

\section{Physical health}

The findings indicate that regular exercise is connected to an increased belief that health is under one's control. The powerful others dimension of health locus of control was also found to have high significant relationship with physical health implying that school authorities should take an active role in influencing students to participate in extra curricular activity and encourage students to cycle or walk to school rather than commute by bus etc.

\section{Protective behavior}

The results for this dimension illustrate that a stronger sense of support from peer and family is perceived by adolescents who have internal and powerful others' locus of control. Similar studies that have examined the interaction effect between health behavior and health locus of control have generally produced positive results. ${ }^{22,26}$ 


\section{Sexual behavior}

The results imply that adolescents with strong belief that health is under their control are less likely to indulge in unsafe sexual behavior. At the same time if adolescents believe health is controlled by the health professional and parents, the chance of practising unsafe sex is lesser.

\section{Implications of the research}

Results of this study could be used for prediction of how to modify positive health behaviors of adolescent students for the protection and promotion of their health. Further, understanding how adolescents' personal belief about who or what affects his/her health will be useful for teachers, parents and counsellors. This understanding emphasizes the importance of adolescents' individual responsibility for health, especially in the school years which represent a 'critical period' for students to adopt healthy behaviors and lifestyles.

The results not only clearly indicate the relationship between HLOC and positive health behaviors of adolescent students, but also support the results of earlier research. School psychologists and health educators need to emphasize HLOC in educational activities for reduction of unhealthy behaviors. Having a stronger sense of control over one's own life seems to be a protective factor for some aspects of health in adult life. Thus, the findings of the study open directions for longitudinal research in continuously assessing for changes in health locus and health behaviors in future. The sub-dimensions of health behaviors that interact with the facets of health locus of control may be important not only for theory development, but also in the design of future health promotion intervention strategies.

\section{Strengths and Limitations of the study}

The strengths of this study are its sample size, resulting in high representativeness of the sample, with a high degree of generalizability for the adolescent population within the age range of 13-16 years. There are also some limitations. First, data on their health behavior patterns were self reported without using any objective measures to assess their observable indicators of health such as height, weight, medical history and records. Secondly, the sample consisted of adolescents hailing from lower and middle class families representing the government schools. The socio- economic and educational backgrounds of this sample significantly differ compared to the sample usually representing private and aided schools in urban settings.

\section{CONCLUSION}

The two dimensions of health locus of control viz internal locus of control and powerful others is significantly correlated with the different dimensions of positive health behavior. A high inclination towards internal health locus of control and powerful others indicates better level of positive health behavior. Significantly, students who believed that they themselves and their health providers had more control over their health had better personal hygiene, were less likely to get involved in violent behavior, less likely to develop psychological problems, to a great extent avoid tobacco use, and alcohol abuse, practice regular exercise, perceive a strong sense of protective behaviors aspects from their parents and peer group and finally, less expected to encounter unsafe sexual practices.

\section{Conflict of Interest Notification}

There are no conflicts of interest in the study conducted.

\section{REFERENCES}

1. Mosby's Medical Dictionary. $7^{\text {th }}$ ed. St. Louis, MO: Mosby; 2005.

2. Karen Glanz, Jay Maddock. The Gale Group Inc, Macmillan Reference USA, New York; 2002.

3. Kasl S V, and Cobb S. Health Behavior, Illness Behavior, and Sick-Role Behavior: II. Sick-Role Behavior. Archives of Environmental Health. 1966; 12, 531-541.

4. Gochman D S. Health Behavior Research: Definitions and Diversity. In D. S. Gochman (ed.), Handbook of Health Behavior Research, Vol. I. Personal and Social Determinants. New York. Plenum Press; 1997.

5. William R Brieger, Delano, Grace E Lane, Catherine G, Oladepo Oladimeji, Oyediran Kola A. West African Youth Initiative: Outcome of a reproductive health education program. Journal of Adolescent Health. 2001; Vol 29(6), pp. 436-446

6. Rotter J B. Generalised expectancies of internal versus external control of reinforcements. Psychological monographs; 1966.

7. Lefcourt H M. Locus of Control: Current Trends in Theory and Research New Jersey: Lawrence Erlbaum Associates; 1976.

8. Norman, P. and Bennett, P. Health Locus of Control Models. In Conner, M. and Norman, P. (eds), Predicting Health Behavior: Research and Practice with Social Cognition Models. Open University Press, Buckingham; 1995.

9. Ferraro LA, Price JH, Desmond Sm, Robert SM. Development of diabetes locus of control scale, Psychological Rep. 1987; Dec; 61 93; 763-70

10. Bradley C, Lewis K S, Jennings A M, Ward, J D. Scales to Measure Perceived Control Developed Specifically for People with Tablet-treated Diabetes. Diabetic Medicine. 1990; 7:685-694.

11. Grant M, Hezekiah J. Knowledge and beliefs about hypertension among Jamaican female clients, International Journal of Nursing Studies. 1996; 33 (1), pp. 58-66.

12. Maltby J, Day L, Macaskill. A. Personality, Individual Differences and Intelligence. Harlow: Pearson Prentice Hall; 2007.

13. Steptoe A, Wardle J, Vinck J, Tuomisto M, Holte A, Wickstrom L. Personality and attitudinal correlates of healthy and unhealthy lifestyles in young adults. Psychology and Health. 1994; 9, 331-343.

14. Bennett P, Norman P, Moore L, Murphy S, Tudor-Smith C. Health locus of control and value for health in smokers and nonsmokers, Health Psychology. 1997; 16(2):179-82.

15. U.S. Department of Health and Human Services. Health risk behaviors among adolescents who do and do not attend school--United States. Morbidity and Mortality Weekly Report, 1994; 43(8), 129-131.

16. WHO, Programming for adolescent health and development', report of a WHO/UNFPA/UNICEF study group on Programming for Adolescent Health; 1999.

17. WHO. The world report -Reducing risks, Promoting Healthy Life; 2002.

18. Wallston K A, Wallston B S, DeVellis R. Development of the multidimensional health locus of control. Health Education Monographs. $1978 ; 6,160-170$. 
19. Romate J, Veena G R, Gayathri S, Sudha Bhogle. Knowledge of AIDs transmission and Correlates of health behavior in Adolescents. Dissertation in Bangalore university; 2006.

20. Granner ML, Sargent RG, Calderon KS, Hussey JR, Evans AE, Watkins $\mathrm{KW}$. Factors of fruit and vegetable intake by race, gender, and age among young adolescents. J Nutr Educ Behav. 2004; Jul-Aug; 36(4):173-80.

21. Vijayapushpam T, Menon KK, Raghunatha Rao D, Maria Antony G. A qualitative assessment of nutrition knowledge levels and dietary intake of schoolchildren in Hyderabad. Public Health Nutr. 2003; $6(7): 683-8$.

22. Weiss G L, Larsen D L. Health value, health locus of control, and the prediction of health protective behaviors. Social Behavior and Personality. 2003; 18, 121-136.

23. Bojanić J, Matović-Miljanović S, Janković S, Jandrić L, Raznatović-Durović M. Zavod za zastitu zdravlja Republike Srpske, Banja Luka. Violence and injuries among school children in the Republic of Serbia][Article in Serbian. Med Pregl. 2006; 59(7-8):305-8.

24. Aubee, Beatrix Huberta. Locus of control, antisocial attitudes, mental health diagnosis, suicidal ideation, depression, anxiety, intellectual functioning, and revenue source as predictors of length of stay of adolescent psychiatric inpatients. Dissertation submitted to Tennessee State University; 1999.

25. Eiser JR, Eiser C, Gammage P, Morgan M. Health locus of control and health beliefs in relation to adolescent smoking, $\mathrm{Br} \mathrm{J}$ Addict. 1989; 84(9):1059-65.Links

26. Bennett P, Norman P, Moore L, Murphy S, Tudor-Smith C. Health locus of control and value for health in smokers and nonsmokers, Health Psychology. 1997; 16(2):179-82.

27. Kim, Young-Ho. Korean adolescents' health risk behaviors and their relationships with the selected psychological constructs. Journal-ofAdolescent-Health. 2001; Vol 29 (4):298-306 